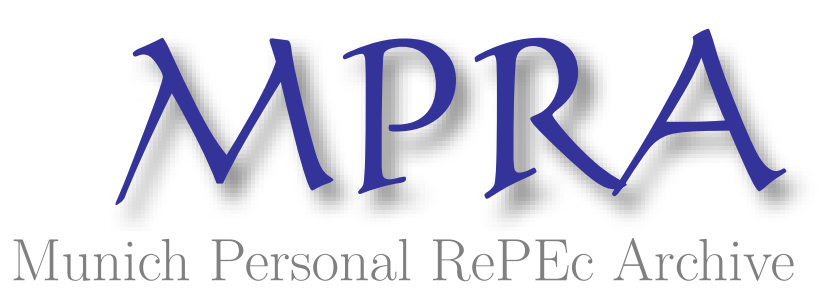

Price and Payoff Autocorrelations in the
Consumption-Based Asset Pricing Model

Olkhov, Victor

Independent

5 March 2022

Online at https://mpra.ub.uni-muenchen.de/112255/

MPRA Paper No. 112255, posted 08 Mar 2022 03:24 UTC 


\title{
Price and Payoff Autocorrelations \\ in the Consumption-Based Asset Pricing Model
}

\author{
Victor Olkhov \\ Moscow, Russia \\ victor.olkhov@gmail.com \\ ORCID: 0000-0003-0944-5113
}

\begin{abstract}
This paper considers common consumption-based asset pricing model and derives approximations of the basic pricing equation that describes mutual dependence of the mean price "to-day", mean payoff "next-day", price and payoff volatility and impact of the price and payoff autocorrelations. The deep conjunction of the consumption-based model with other modifications of asset pricing as ICAPM, APM and etc. (Cochrane, 2001) causes that our results can be derived in other versions of CAPM. We introduce the market-based price averaging and discuss the origin of its distinctions from the common frequency-based price probability. The market-based price statistical moments, price volatility and autocorrelation are determined by statistical moments of the random market trade value and volume. Distinctions between the frequency-based and the market-based approaches to price averaging cause different assessment of the price volatility and autocorrelation and result in different treatment of the price-volume relations in particular. The market-based price averaging provides direct dependence of the price statistical moments on the market trade value and volume statistical moments. It establishes a unified ground for description of financial markets but uncovers tough complexity. The usage of the frequency-based or proposed market-based price averaging is completely determined by agent's preferences, beliefs and habits. The collision between "rational" market-based approach and "soulful" or "home-felt" frequency-based approach to price averaging creates significant challenge for financial theory.
\end{abstract}

Keywords : asset pricing, autocorrelation, price probability, market trades

JEL: G12

This research received no financial support or assistance from funding agencies in the public, commercial or nonprofit sectors. We welcome any help. 


\section{Introduction}

This paper shows that the conventional consumption-based pricing model can assess price and payoff autocorrelations. Most investors are looking for "signs" that price movements will follow their expectations up or down. Most market researchers develop pricing models that should "predict" the price variations. The third party of that market price gamble incorporates economic and financial authorities that divine and augur short and long term market consequences of their regulatory actions. All parties follow almost the same economic theories but aim to opposite goals. And what is the most amazing, that each party disturbs the market price in a way that violates the predictions of others. Market stochasticity "clears" impact of all parties and produces an incredible and complex object for financial studies and modelling. And that complexity increases with each new market theory and regulator's action.

Studies of the price autocorrelation and price correlation with other economic variables are among the most wanted. Many researches study the market price-volume relations (Fama, 1965; Lo, 1987; Liu et.al., 1997; Plerou et.al., 2000; Goetzmann, Li and Rouwenhorst, 2001; Quinn and Voth, 2008). Studies of the market price correlations are part of more general and old problem - estimating correlations between different economic and financial variables (King, 1917; Kendall and Hill, 1953; Friedman, 1962; Fama, 1965; Michaely, 1971; Lo, 1987; Campbell, Grossman, and Wang, 1992; Liu et.al., 1997; Mantegna and Stanley, 2000; Plerou et.al., 2000; Goetzmann, Li and Rouwenhorst, 2001; Llorente et.al., 2001; Andersen et.al., 2006; Quinn and Voth, 2008; Diebold and Strasser, 2010; Lind and Ramondo, 2018). Any attempt to review the economic correlation studies requires a separate and deep research. This paper is not an introductory for beginners and we assume that our readers are familiar enough with conventional asset pricing models as (Goldsmith and Lipsey, 1963; Sharpe, 1964; Merton, 1973; Friedman, 1990; Campbell, 2000; Cochrane, 2001; Cochrane and Culp, 2003; Campbell, 2014; Fama, 2014; Barillas and Shanken, 2018; Cochrane, 2022) and current studies of correlations between economic and financial variables. We propose that readers are familiar with basic tools and terms of probability theory, statistical moments, characteristic function and etc.

Description of the price autocorrelation is an important part of the random market price studies. We consider two basic problems that establish the major part of the market price stochastic puzzle: the pricing model and the pricing averaging procedure. Indeed, any statistical assessments of correlation between market price time-series and time-series that determine other economic variable like market trade volume in particular, use some specific 
averaging procedure. We assume that the choice of the averaging procedure primarily should follow economic and market meaning of the particular variable. Actually, the market timeseries establish econometric origin of any investigations of the random price properties. Any market price assessments and predictions utilize time-series received by different aggregation, smoothing and averaging of the initial market time-series records. The choice of the method that aggregates initial market time-series and produces the averaged, smooth and slowly changing market relations hides a lot complexity (Olkhov, 2021a - 2022).

Econometric assessments of autocorrelation of the market price time-series should be complemented by theoretical models and estimates. In particular it seems reasonable that pricing theories should generate definite approximations of the price autocorrelation. With this in mind we consider the conventional consumption-based pricing model and show that standard assumptions on utility function allows derive expressions of the price and payoff autocorrelation. Consumption-based model (Cochrane, 2001) is very similar to other versions of the asset pricing as Intertemporal CAMP (ICAPM), Arbitrage pricing theory (APT) and etc. Thus, Cochrane's (2001) study allows assert that our results also can be derived within other asset pricing models as well.

The main contribution of this paper - derivation of the approximations of the basic pricing equations those describe relations between the mean price today at time $t$, mean payoff "next day" at time $T$, price and payoff volatilities at $t$ and $T$. We show that the basic pricing equations can depend on price autocorrelation at times $t_{1}$ and $t_{2}$ and on payoff autocorrelation at times $T_{1}$ and $T_{2}$.

Further we show that the price statistical moments should be determined by the market trade statistical moments and denote it as the market-based price averaging. We underline, that distinctions between conventional frequency-based and proposed market-based price averaging result in different treatment of the price-volume relations in particular. Marketbased averaging does not simplify the problem but establishes direct dependence of price statistical moments, price volatility and autocorrelation on statistical moments of random market trade value and volume.

\section{Covert issues of the asset pricing}

We consider common consumption-based asset pricing and follow well-known manual (Cochrane, 2001) as the main source for any details. Cochrane's study presents clear and complete description of the pricing models and describes numerous cases as well as demonstrates the unity of most variations of asset pricing. Thus we believe that our new 
results can be derived within other variations of asset pricing. We take study by Cochrane (2001) as the basic source and show that the initial assumptions on the price averaging procedure and the form of the utility function hide certain issues that generate interesting pricing relations. We present simple modifications of the usual asset averaging procedure and investor's utility function and derive extensions of the basic equation. That causes modification of the "main statement" of the asset pricing - "Price equals expected discounted payoff" and presents assessments of price autocorrelation.

Let us start with Cochrane's (2001) model of investor's behavior via utility function $u\left(c_{t}\right)$ at current day $t$ and utility $u\left(c_{T}\right)$ "next day" $T$ and keep almost all notations:

$$
\begin{gathered}
U\left(c_{t} ; c_{T}\right)=u\left(c_{t}\right)+\beta E\left[u\left(c_{T}\right)\right] \\
c_{t}=e_{t}-p \xi ; \quad c_{T}=e_{T}+x_{T} \xi ; \quad x_{T}=p_{T}+d_{T}
\end{gathered}
$$

In (2.1) $E[.$.$] denotes math expectation at day T$ under the information available at day $t$ and $\beta$ is subjective discount factor. $c_{t}$ and $c_{T}$ denote consumptions at day $t$ and $T, p_{t}, p_{T}-$ asset prices at $t$ and $T, d_{T}$ and $x_{T}$ - dividend and payoff at day $T$. $e_{t}$ and $e_{T}-$ consumption at $t$ and at $T$ without investments. $\xi$ - amount of assets investor purchases at day $t$ and sells at day $T$. Standard consumption-based model (Cochrane, 2001) considers max of the utility (2.1) by amount of assets $\xi$ as condition that derives the basic pricing equation (2.4):

$$
\begin{gathered}
\max _{\xi} U\left(c_{t} ; c_{t+1}\right) \leftrightarrow \frac{\partial}{\partial \xi} U\left(c_{t} ; c_{t+1}\right)=0 \\
p=\beta E\left[\frac{u^{\prime}\left(c_{T}\right)}{u^{\prime}\left(c_{t}\right)} x\right]=E[m x] \\
m=\beta \frac{u^{\prime}\left(c_{T}\right)}{u^{\prime}\left(c_{t}\right)} \quad ; \quad u^{\prime}(c)=\frac{d}{d c} u(c)
\end{gathered}
$$

The basic pricing equation (2.4) is the origin of popular statement: "Price equals expected discounted payoff" (Cochrane, 2001). Now, let us reconsider (2.1-2.5) taking into account the meaning of mathematical expectation $E[.$.$] .$

Indeed, all market trade data are presented by time-series and any averaging procedure aggregates members of the time-series during certain time interval $\Delta$. Let market price $p\left(t_{i}\right)$ time-series to be determined at time points $t_{i}$ with time shift $\varepsilon$ :

$$
t_{i}=\varepsilon \cdot i ; i=0,1,2, \ldots
$$

Hence, time scale $\varepsilon$ determines min division of the time axis of the problem. Aggregation or averaging of time-series during the interval $\Delta$ replaces the initial time axis divisions multiple of $\varepsilon$ by time divisions multiple of the averaging scale $\Delta$. Such change of the time axis divisions cannot be performed at "the next day" $T$ only, but should change time axis at day $t$ also. It seems reasonable, that the problem should be described by the time axis with the 
unified time divisions along the entire time axis. Thus any averaging during the interval $\Delta$ performed by math expectation $E[.$.$] at day T$ should be complemented by the similar averaging during the same interval $\Delta$ at day $t$. That replaces the investor's utility function (2.1) by

$$
U\left(c_{t} ; c_{T}\right)=E\left[u\left(c_{t}\right)\right]+\beta E\left[u\left(c_{T}\right)\right]
$$

In (2.7) $E\left[u\left(c_{t}\right)\right]$ denotes math expectation at day $t$ and $E\left[u\left(c_{T}\right)\right]$ - math expectation at day $T$ both performed during the same averaging interval $\Delta$. Averaging during same interval $\Delta$ at days $t$ and $T$ establishes same divisions multiple of $\Delta$ of the time axis.

If the amount of assets $\xi$ deliver max to investor's utility (2.7) then (2.4) is replaced by the modified basic equation (2.8):

$$
E\left[u^{\prime}\left(c_{t}\right) p\right]=\beta E\left[u^{\prime}\left(c_{T}\right) x\right]
$$

We remind that $E[.$.$] in the left side of (2.8) denotes math expectation at day t$ and $E[.$.$] in the$ right side (2.8) denotes math expectation at day $T$ under the information available at day $t$.

Direct assessment of math expectations in (2.8) is a rather difficult problem. To simplify it let us derive approximation of (2.8) using simple Taylor series.

\section{Approximation of the basic pricing equation}

To derive approximation of the basic equation (2.8) let present the utility functions during the averaging interval $\Delta$ at day $t$ and at day $T$ using Taylor series by variations of price at day $t$ and variations of payoff at day $T$. Indeed, averaging $E[.$.$] during \Delta$ assumes that price $p$ at day $t$ and payoff $x$ at day $T$ during $\Delta$ can be presented as

$$
p=p_{0}+\delta p ; \quad x=x_{0}+\delta x
$$

Here $p_{0}$ is a mean price at day $t$ during the averaging interval $\Delta$ and $\delta p$ - price variations near the mean $p_{0}$ during $\Delta$. We use the similar notations for the mean payoff $x_{0}$ and the payoff variations $\delta x$ during $\Delta$ at day T. Relations (3.2) determine the mean price $p_{0}$, mean payoff $x_{0}$, price volatility $\sigma_{p}^{2}(t)$ at day $t$ and payoff volatility $\sigma_{x}^{2}(T)$ at day $T$.

$$
p_{0}=E[p] ; x_{0}=E[x] ; E[\delta p]=E[\delta x]=0 ; \sigma_{p}^{2}(t)=E\left[\delta^{2} p\right] ; \sigma_{x}^{2}(T)=E\left[\delta^{2} x\right]
$$

Relations $(2.2 ; 3.1 ; 3.2)$ allow present Taylor series for the utility functions (2.8). Here we consider only simplest linear expansion of Taylor series

$$
\begin{array}{ll}
u^{\prime}\left(c_{t}\right)=u^{\prime}\left(c_{t ; 0}\right)-u^{\prime \prime}\left(c_{t ; 0}\right) \xi \delta p & ; \quad c_{t ; 0}=e_{t}-p_{0} \xi \\
u^{\prime}\left(c_{T}\right)=u^{\prime}\left(c_{T ; 0}\right)+u^{\prime \prime}\left(c_{T ; 0}\right) \xi \delta x & ; \quad c_{T ; 0}=e_{T}+x_{0} \xi
\end{array}
$$

Substitution of the linear Taylor series $(3.3 ; 3.4)$ of the utility functions $(2.7)$ into $(2.8)$ and (3.2) gives the linear approximation of the basic pricing equation (2.8) as:

$$
p_{0}(t)=\beta \frac{u^{\prime}\left(c_{T ; 0}\right)}{u^{\prime}\left(c_{t ; 0}\right)} x_{0}(T)+\beta \xi \frac{u^{\prime \prime}\left(c_{T ; 0}\right)}{u^{\prime}\left(c_{t ; 0}\right)} \sigma_{x}^{2}(T)+\xi \frac{u^{\prime \prime}\left(c_{t ; 0}\right)}{u^{\prime}\left(c_{t ; 0}\right)} \sigma_{p}^{2}(t)
$$


Approximation of the basic equation (3.5) establishes direct dependence of the mean price $p_{0}(t)$ at day $t$ on the discounted mean payoff $x_{0}(T)$ at day $T$. However approximation (3.5) also determines dependence of the mean price $p_{0}$ at day $t$ on price volatility $\sigma_{p}^{2}(t)$ at day $t$ and payoff volatility $\sigma_{x}^{2}(T)$ at day $T$. Taking into account that the second derivative of the utility always should be negative obtain obvious condition that growth of the price volatility $\sigma_{p}{ }^{2}(t)$ or payoff volatility $\sigma_{x}^{2}(T)$ should lower the mean price $p_{0}$ at day $t$.

It can be noted that (3.5) presets the direct linear dependence of the mean price $p_{0}$ at day $t$ on the amount of assets $\xi$. However, dependence on $\xi$ is also hidden in the form of the consumption $(3.3 ; 3.4)$ and the basic pricing equation $(2.4)$ due to $(2.2)$ also depends on the amount of assets $\xi$. It is obvious, that the discount factor $m$ (2.5) (Cochrane, 2001) has hidden dependence on the amount of assets $\xi$ that delivers max to investor's utility (1.1). Complexity of that dependence and complexity of the assessment of the math expectation in (2.5) that takes into account dependence on $\xi$ results in omitting these relations and consideration of the discount factor $m(2.5)$ as a "given". Actually, even determination of $\xi$ that delivers max to investor's utility (1.1) is a tough problem that requires separate calculations Olkhov (2021a 2021c).

Now let consider modification of the utility (2.7) that helps assess price autocorrelation.

\section{Price autocorrelation}

Economic considerations that justify investor's utility in the form (2.1) or (2.7) are rather simple. Investor chooses between consumption $e_{t}$ at day $t$ and consumption $e_{T}$ at day $T$ without investment or consumption (2.2) within investment. The investor's utilities $(2.1 ; 2.7)$ and the basic equations $(2.4 ; 2.8)$ model the case with a single purchase and a single sale of assets. However, investor can take a decision to purchase assets twice during some time interval $l$ and sell all assets at the same day $T$. How can one model that case using standard investor's utility (2.1) or (2.7)?

We model two purchases and single sale of assets by two utilities and two basic equations. The model of first purchase at time $t_{1}$ and sale of the assets at $T$ is coincides (4.2) with above utility (2.7) and consumption (2.2):

$$
\begin{gathered}
c_{t_{1}}=e_{t_{1}}-p\left(t_{1}\right) \xi\left(t_{1}\right) \quad ; \quad c_{T}=e_{T}+x_{1} \xi\left(t_{1}\right) ; x_{1}=x_{1 ; 0}+\delta x_{1} \\
E\left[u^{\prime}\left(c_{t_{1}}\right) p\left(t_{1}\right)\right]=\beta E\left[u^{\prime}\left(c_{T}\right) x_{1}\right]
\end{gathered}
$$

In $(4.1 ; 4.2) x_{1 ; 0}$ and $\delta x_{1}$ denote assessments of the mean payoff and payoff variations under information available at time $t_{l}$. 
We model the second purchase at time $t_{2}$ and sale of the assets at the same day $T$ by utility (2.7) and consumption (4.2). At time $t_{2}$ the forecast of the mean payoff and payoff variations can be different from the forecast made at time $t_{1}$. Thus, at time $t_{2}$ we model consumption as:

$$
c_{t_{2}}=e_{t_{1}}-p\left(t_{1}\right) \xi\left(t_{1}\right)-p\left(t_{2}\right) \xi\left(t_{2}\right) ; c_{T}=e_{T}+x_{2}\left[\xi\left(t_{1}\right)+\xi\left(t_{2}\right)\right] \quad ; t_{2}=t_{1}+l
$$

Relations (4.3) model the assumption that investor does not change his consumption since $t_{1}$ during time interval $l$ that defines the time $t_{2}$ of the second purchase. Relations (4.3) does not change the form of the basic equation (2.8) and (4.2) determined by max condition of utility (2.7) by amount of assets $\xi\left(t_{2}\right)$ :

$$
E\left[u^{\prime}\left(c_{t_{2}}\right) p\left(t_{2}\right)\right]=\beta E\left[u^{\prime}\left(c_{T}\right) x_{2}\right]
$$

The basic equations (4.2) and (4.4) describe max of investor's utility (2.7) at first and the second purchases and are similar to the basic equation (2.8) of the single purchase. It seems that nothing change. However, linear Taylor series approximations show that (4.3) and (4.4) give assessment of the price autocorrelation. To show that present price and payoff as:

$$
p\left(t_{1}\right)=p_{0}\left(t_{1}\right)+\delta p_{1} \quad ; \quad p\left(t_{2}\right)=p_{0}\left(t_{2}\right)+\delta p_{2} ; x_{2}=x_{2 ; 0}+\delta x_{2}
$$

Now take linear Taylor series approximation of utilities in $(4.4)$ due to $(4.3 ; 4.5)$ :

$$
\begin{gathered}
u^{\prime}\left(c_{t_{2}}\right)=u^{\prime}\left(c_{t_{2} ; 0}\right)-u^{\prime \prime}\left(c_{t_{2} ; 0}\right)\left[\xi\left(t_{1}\right) \delta p_{1}+\xi\left(t_{2}\right) \delta p_{2}\right] \\
u^{\prime}\left(c_{T}\right)=u^{\prime}\left(c_{T ; 0}\right)+u^{\prime \prime}\left(c_{T ; 0}\right)\left[\xi\left(t_{1}\right)+\xi\left(t_{2}\right)\right] \delta x_{2} \\
c_{t_{2 ; 0}}=e_{t_{1}}-p_{0}\left(t_{1}\right) \xi\left(t_{1}\right)-p_{0}\left(t_{2}\right) \xi\left(t_{2}\right) ; c_{T ; 0}=e_{T}+x_{2 ; 0}\left[\xi\left(t_{1}\right)+\xi\left(t_{2}\right)\right] \\
p_{0}\left(t_{1}\right)=E\left[p\left(t_{1}\right)\right] ; p_{0}\left(t_{2}\right)=E\left[p\left(t_{2}\right)\right] ; \sigma_{p}^{2}\left(t_{1}\right)=E\left[\delta^{2} p_{1}\right] ; \sigma_{p}^{2}\left(t_{2}\right)=E\left[\delta^{2} p_{2}\right] \\
\sigma_{x_{2}}^{2}(T)=E\left[\delta^{2} x_{2}\right] ; \quad B_{p}\left(t_{1}, t_{2}\right)=E\left[\delta p_{1} \delta p_{2}\right] ; E\left[\delta p_{1}\right]=E\left[\delta p_{2}\right]=0
\end{gathered}
$$

The second term in (4.10) describes price autocorrelation at times $t_{1}$ and $t_{2}$.

Taking into account $(3.2 ; 4.9 ; 4.10)$ one obtains that the approximation $(4.11)$ of the basic pricing equation that describes the first purchase at time $t_{l}$ is similar to (3.5).

$$
p_{0}\left(t_{1}\right)=\beta \frac{u^{\prime}\left(c_{T ; 0}\right)}{u^{\prime}\left(c_{t_{1} ; 0}\right)} x_{1 ; 0}+\beta \frac{u^{\prime \prime}\left(c_{T ; 0}\right)}{u^{\prime}\left(c_{t_{1} ; 0}\right)} \xi\left(t_{1}\right) \sigma_{x_{1}}^{2}(T)+\frac{u^{\prime \prime}\left(c_{t_{1} ; 0}\right)}{u^{\prime}\left(c_{t_{1} ; 0}\right)} \xi\left(t_{1}\right) \sigma_{p}^{2}\left(t_{1}\right)
$$

The basic equation (4.11) describes dependence of the mean price $p_{0}\left(t_{1}\right)$ on mean payoff $x_{1 ; 0}$ at time $T$, amount of assets $\xi\left(t_{1}\right)$ that delivers max to utility (2.7) and volatility $\sigma_{p}^{2}\left(t_{1}\right)$ of price at time $t_{1}$ and volatility of payoff $\sigma_{x 1}^{2}(T)$ at time $T$.

Now substitute $(3.2 ; 4.5$ - 4.10) into (4.4) and in the linear approximation by Taylor series of (4.4) obtain the basic equation (4.12) that introduces dependence of the mean price $p_{0}\left(t_{2}\right)$ on price autocorrelation $B_{p}\left(t_{1}, t_{2}\right)$ :

$p_{0}\left(t_{2}\right)=\beta \frac{u^{\prime}\left(c_{T ; 0}\right)}{u^{\prime}\left(c_{t_{2} ; 0}\right)} x_{2 ; 0}+\beta \frac{u^{\prime \prime}\left(c_{T ; 0}\right)}{u^{\prime}\left(c_{t_{2} ; 0}\right)}\left[\xi\left(t_{1}\right)+\xi\left(t_{2}\right)\right] \sigma_{x_{2}}^{2}(T)+\frac{u^{\prime \prime}\left(c_{t_{2} ; 0}\right)}{u^{\prime}\left(c_{t_{2} ; 0}\right)}\left[\xi\left(t_{1}\right) B_{p}\left(t_{1}, t_{2}\right)+\xi\left(t_{2}\right) \sigma_{p}^{2}\left(t_{2}\right)\right]$ 
It should be noted, that the mean payoff $x_{2,0}$ and payoff volatility ${\sigma_{x 2}}^{2}(T)$ at time $T$ in the basic equation (4.12) for the second purchase at time $t_{2}$ can be different from the values that describe the basic equation (4.11) for the first purchase at time $t_{1}$ because they are obtained under information at different times $t_{1}$ and $t_{2}$.

If time interval $l$ between the first purchase at $t_{1}$ the second purchase at time $t_{2}=t_{1}+l$ tends to zero $l \rightarrow 0$ then amount of assets of the second purchase $\xi\left(t_{2}\right) \rightarrow 0$ also tends to zero. Indeed, the fist purchase of $\xi\left(t_{1}\right)$ assets delivers max to utility (2.7) and hence no more assets required during the small time interval $l=t_{2}-t_{1}$. In that case for $l \rightarrow 0, \xi\left(t_{2}\right) \rightarrow 0$ one can neglect $\xi\left(t_{2}\right)$ to compare with $\xi\left(t_{1}\right)$ and equation (4.12) for $t_{2} \rightarrow t_{1}$ takes form:

$$
p_{0}\left(t_{1}\right)=\beta \frac{u^{\prime}\left(c_{T ; 0}\right)}{u^{\prime}\left(c_{t_{1} ; 0}\right)} x_{1 ; 0}+\beta \frac{u^{\prime \prime}\left(c_{T ; 0}\right)}{u^{\prime}\left(c_{t_{1} ; 0}\right)} \xi\left(t_{1}\right) \sigma_{x_{1}}^{2}(T)+\frac{u^{\prime \prime}\left(c_{t_{1} ; 0}\right)}{u^{\prime}\left(c_{t_{1} ; 0}\right)} \xi\left(t_{1}\right) B_{p}\left(t_{1}, t_{1}\right)
$$

Hence, as required, due to (4.11) price autocorrelation in (4.13) match $B_{p}\left(t_{1}, t_{1}\right)=\sigma_{p}^{2}\left(t_{1}\right)$.

Readers can easy derive the step-by-step modifications of the basic pricing equation that describes the case when investor performs $k$ successive purchases of assets at moments $t_{1}, \ldots t_{k}$ and then sell all assets at moment $T$. In this case the basic pricing equation will depend on price autocorrelations $B_{p}\left(t_{i}, t_{j}\right), i, j \leq k$.

\section{Payoff autocorrelation}

Consumption-based asset pricing model determined by investor's utility (2.8) allows describe payoff autocorrelation as well. To show that, let consider the case when investor makes two successive purchases of assets at time $t_{1}$ and $t_{2}$ and then two successive sales of assets at $T_{1}$ and $T_{2}$. Let us model the first purchase and first sale of assets similar to $(4.1 ; 4.2)$ :

$$
c_{t_{1}}=e_{t_{1}}-p\left(t_{1}\right) \xi\left(t_{1}\right) \quad ; \quad c_{T_{1}}=c_{T_{1}}+x_{1}\left(T_{1}\right) \xi\left(t_{1}\right) ; \quad x_{11}\left(T_{1}\right)=x_{11 ; 0}\left(T_{1}\right)+\delta x_{11}
$$

At time $t_{1}$ at price $p\left(t_{1}\right)$ investor purchase the amount $\xi\left(t_{1}\right)$ and sale assets at time $T_{1}$. We denote as $x_{11}\left(T_{1}\right)$ payoff, $x_{11 ; 0}\left(T_{1}\right)$ mean payoff and $\delta x_{11}$ as payoff variations predicted at moment $T_{1}$ under information available at moment $t_{l}$. Investor's utility at time $t_{1}$ takes form:

$$
U\left(c_{t_{1}} ; c_{T_{1}}\right)=E\left[u\left(c_{t_{1}}\right)\right]+\beta E\left[u\left(c_{T_{1}}\right)\right]
$$

The amount $\xi\left(t_{1}\right)$ of assets delivers max to investors utility (5.2) and causes the basic equation

$$
E\left[u^{\prime}\left(c_{t_{1}}\right) p\left(t_{1}\right)\right]=\beta E\left[u^{\prime}\left(c_{T_{1}}\right) x_{11}\left(T_{1}\right)\right]
$$

Then, at time $t_{2}=t_{1}+l$ investor purchases $\xi\left(t_{2}\right)$ of assets and sale these assets at time $T_{2}=$ $T_{1}+L$ at payoff $x_{2}\left(T_{2}\right)$ predicted under information available at time $t_{2}$. We model that case by consumption:

$$
c_{t_{2}}=e_{t_{1}}-p\left(t_{1}\right) \xi\left(t_{1}\right)-p\left(t_{2}\right) \xi\left(t_{2}\right) \quad ; c_{T_{2}}=c_{T_{1}}+x_{12}\left(T_{1}\right) \xi\left(t_{1}\right)+x_{2}\left(T_{2}\right) \xi\left(t_{2}\right)
$$


We denote as $x_{12}\left(T_{1}\right)$ payoff, $x_{12 ; 0}\left(T_{1}\right)$ mean payoff and $\delta x_{12}$ as payoff variations at moment $T_{1}$ predicted under information available at moment $t_{2}$. As $x_{2}\left(T_{2}\right), x_{2 ; 0}\left(T_{2}\right)$ and $\delta x_{2}$ we denote payoff, mean payoff and payoff variations at moment $T_{2}$ predicted under information available at moment $t_{2}$.

$$
x_{12}\left(T_{1}\right)=x_{12 ; 0}\left(T_{1}\right)+\delta x_{12} \quad ; \quad x_{2}\left(T_{1}\right)=x_{2 ; 0}\left(T_{1}\right)+\delta x_{2}
$$

Investor's utility at moment $t_{2}$ takes form:

$$
U\left(c_{t_{2}} ; c_{T_{2}}\right)=E\left[u\left(c_{t_{2}}\right)\right]+\beta E\left[u\left(c_{T_{2}}\right)\right]
$$

Relations $(5.4 ; 5.5)$ and assumption that $\xi\left(t_{2}\right)$ at time $t_{2}$ delivers max to investors utility (5.6) causes the basic equation (5.7):

$$
E\left[u^{\prime}\left(c_{t_{2}}\right) p\left(t_{2}\right)\right]=\beta E\left[u^{\prime}\left(c_{T_{2}}\right) x_{2}\left(T_{2}\right)\right]
$$

Linear Taylor series by price and payoff variations of utility functions similar to $(4.6 ; 4.7)$ allow derive approximations of the basic equations $(5.2 ; 5.5)$ :

$$
\begin{gathered}
p_{0}\left(t_{1}\right)=\beta \frac{u^{\prime}\left(c_{T 1 ; 0}\right)}{u^{\prime}\left(c_{t_{1} ; 0}\right)} x_{11 ; 0}\left(T_{1}\right)+\beta \frac{u^{\prime \prime}\left(c_{T 1 ; 0}\right)}{u^{\prime}\left(c_{t_{1} ; 0}\right)} \xi\left(t_{1}\right) \sigma_{x_{11}}^{2}\left(T_{1}\right)+\frac{u^{\prime \prime}\left(c_{t_{1} ; 0}\right)}{u^{\prime}\left(c_{t_{1} ; 0}\right)} \xi\left(t_{1}\right) \sigma_{p}^{2}\left(t_{1}\right) \\
\sigma_{x_{11}}^{2}\left(T_{1}\right)=E\left[\delta^{2} x_{11}\right] ; \sigma_{x_{2}}^{2}\left(T_{1}\right)=E\left[\delta^{2} x_{2}\right] \\
p_{0}\left(t_{2}\right)=\beta \frac{u^{\prime}\left(c_{T 2 ; 0}\right)}{u^{\prime}\left(c_{t_{2} ; 0}\right)} x_{12 ; 0}+\beta \frac{u^{\prime \prime}\left(c_{T 2 ; 0}\right)}{u^{\prime}\left(c_{t_{2} ; 0}\right)}\left[\xi\left(t_{1}\right) B_{x}\left(T_{1}, T_{2}\right)+\xi\left(t_{2}\right) \sigma_{x_{2}}^{2}\left(T_{2}\right)\right]+\frac{u^{\prime \prime}\left(c_{t_{2} ; 0}\right)}{u^{\prime}\left(c_{t_{2} ; 0}\right)}\left[\xi\left(t_{1}\right) B_{p}\left(t_{1}, t_{2}\right)+\right. \\
\left.\xi\left(t_{2}\right) \sigma_{p}^{2}\left(t_{2}\right)\right]
\end{gathered}
$$

Payoff autocorrelation $B_{x}\left(T_{1}, T_{2}\right)$ is determined as math expectation (5.9) of payoff variations $\delta x_{12}$ at moment $T_{1}$ and $\delta x_{2}$ at moment $T_{2}$ predicted under information available at $T_{2}$.

$$
B_{x}\left(T_{1}, T_{2}\right)=E\left[\delta x_{12}\left(T_{1}\right) \delta x_{2}\left(T_{2}\right)\right]
$$

Price autocorrelation $B_{p}\left(t_{1}, t_{2}\right)$ is determined by (4.10).

Readers can extend the above results and derive the step-by-step modifications of the basic pricing equation that describes the case when investor performs $k$ successive purchases of assets at moments $t_{1}, \ldots t_{k}$ and then $\mathrm{k}$ successive sales of assets at times $T_{1}, \ldots T_{k}$. In this case the basic pricing equation will depend on price autocorrelations $B_{p}\left(t_{i}, t_{j}\right)$ and on payoff autocorrelation $B_{x}\left(T_{i}, T_{j}\right), i, j \leq k$.

\section{Market-based averaging}

In this section we consider the problems, hidden inside the obvious and simple notion of the mathematical expectation $E[.$.$] that is used to assess the mean price, price volatility and etc.$ Indeed, all financial variables and market trade data are presented by time-series at time points $t_{i}$ alike to (2.6). The time lag $\varepsilon$ (2.6) determines the min division of the time axis. Any math expectation $E[.$.$] delivers certain aggregation of the time-series values during some$ time interval $\Delta$. The conventional consideration of math expectation $E[.$.$] "is based on the$ 
probabilistic approach and using A. N. Kolmogorov's axiomatic of probability theory, which is generally accepted now" (Shiryaev 1999). The frequency of the event defines the origin of conventional probability. For example, if market trades at price $p$ during time interval $\Delta$ occur $n$ times and total number of trades during $\Delta$ equals $N$ then frequency-based probability $P(p)$ of price $p$ assumed to be

$$
P(p) \sim \frac{n}{N} \quad ; \quad E[p]=\sum P(p) p
$$

Taking into account (2.6) one can chose

$$
\begin{gathered}
\Delta=2 k \varepsilon \quad ; N=2 k+1 ; \quad \Delta=\left[t-\frac{\Delta}{2}, t+\frac{\Delta}{2}\right] \\
t_{1}=t-\frac{\Delta}{2} ; \quad t_{i}=t_{1}+(i-1) \varepsilon \quad ; \quad i=1, \ldots N
\end{gathered}
$$

Standard consideration of the frequency-based probability (6.1) for the price time series $p\left(t_{i}\right)$ results in the definition of the mean price $p(t ; 1)$ during the averaging interval $\Delta$

$$
p(t ; 1)=\frac{1}{N} \sum_{i=1}^{N} p\left(t_{i}\right) \quad ; \quad t_{i} \in \Delta, \quad i=1, \ldots N
$$

Relations $(6.1 ; 6.4)$ give simple definition for the most conventional treatment of the frequency-based approach to the price probability and almost all standard probability measures (Walck, 2007; Forbes et.al., 2011) where checked to test how they fit the random market price properties.

However, conventional frequency-based approach is not the only one and seems to be not the correct one to describe the properties of the random market price. Indeed, market price $p\left(t_{i}\right)$ at time $t_{i}$ is a result of market trade determined by trivial relations (6.5) between the trade value $C\left(t_{i}\right)$ and volume $U\left(t_{i}\right)$ :

$$
C\left(t_{i}\right)=p\left(t_{i}\right) U\left(t_{i}\right)
$$

The frequency-based probability approach defines the mean value $C(t ; 1)$ and the mean volume $U(t ; 1)$ of $N(6.2 ; 6.3)$ market trades performed during the averaging interval $\Delta$ :

$$
C(t ; 1)=\frac{1}{N} \sum_{i=1}^{N} C\left(t_{i}\right) \quad ; \quad U(t ; 1)=\frac{1}{N} \sum_{i=1}^{N} U\left(t_{i}\right)
$$

However, relations (6.5) prohibit independent definitions of probabilities and statistical moments of the trade value $C\left(t_{i}\right)$, volume $U\left(t_{i}\right)$ and price $p\left(t_{i}\right)$ determined by their time series. The given probabilities of the market trade value and volume, relations (6.5) should define the market price probability and thus all price statistical moments.

The description of numerous irregular economic and financial variables is a general nature problem. Economics is a complex system of numerous agents with a great number of variables. Agents perform various market trades and that cause change of agent's variables. Description of economic variables should follow the unified approach. All macroeconomic 
and financial variables are composed as aggregation of corresponding agent's variables both by economic properties and during some time interval $\Delta$. Macroeconomic consumption, credits and investment during quarter or year are determined as sums (without repeating and doubling) of consumption, credits and investment during quarter or year of all agents in the entire economy. We note such economic variables as additive, because the sum of these variables of certain group of agents defines the variables of the entire group. For example, the profits of a particular industry during a year are determined as sum during the year of all profits (without repeating and doubling) of all agents that belong to that industry. We present the simplified meaning of the economic aggregation problem and refer (Fox, et.al., 2019) for correct consideration of the aggregation methodologies. Trade value and volume are also additive variables as sums of values and volumes of all trades during certain time interval $\Delta$ define aggregate trade value and volume during $\Delta$. However, market price is not additive variable. To define the mean market price during the interval $\Delta$ one should take (6.5) for the sums or for the mean trade value and volumes:

$$
C(t ; 1)=p(t ; 1) U(t ; 1)
$$

One can easy find out that the mean price $p(t ; 1)(6.7)$ for the mean trade value $C(t ; 1)$ and volume $U(t ; 1)(6.6)$ completely coincides with well known volume weighted average price (VWAP) that was introduced at least 30 years ago (Berkowitz, et al., 1988; Buryak and Guo, 2014; Busseti and Boyd, 2015) and widely used now (Nasdaq, 2020; CBOE, 2021a, 2021b). For $N$ trades performed during the averaging interval $\Delta \operatorname{VWAP} p(t ; 1)$ has simple definition as

$$
p(t ; 1)=\frac{\sum_{i=1}^{N} p\left(t_{i}\right) U\left(t_{i}\right)}{\sum_{i=1}^{N} U\left(t_{i}\right)}=\frac{C(t ; 1)}{U(t ; 1)}
$$

However, to define the price probability during the given interval $\Delta$ one should define all price statistical moments. To do that let take the $n$-th power of (6.5) for the single trade at $t_{i}$ :

$$
C^{n}\left(t_{i}\right)=p^{n}\left(t_{i}\right) U^{n}\left(t_{i}\right) ; n=1,2, \ldots
$$

Now average both sides of (6.9) and assume that time-series of the $n$-th power of price $p^{n}\left(t_{i}\right)$ do not correlate with $n$-th power of trade volume $U^{n}\left(t_{i}\right)$ time-series during the interval $\Delta$.

$$
E\left[C^{n}\left(t_{i}\right)\right]=E\left[p^{n}\left(t_{i}\right) U^{n}\left(t_{i}\right)\right]=E\left[p^{n}\left(t_{i}\right)\right] E\left[U^{n}\left(t_{i}\right)\right]
$$

We note $n$-th statistical moments of the trade value $C(t ; n)$ and the trade volume $U(t ; n)$ :

$$
C(t ; n)=\frac{1}{N} \sum_{i=1}^{N} C^{n}\left(t_{i}\right) \quad ; \quad U(t ; n)=\frac{1}{N} \sum_{i=1}^{N} U^{n}\left(t_{i}\right)
$$

Thus from $(6.10 ; 6.11)$ obtain price $n$-th statistical moments $p(t ; n)$ in the form similar to $(6.7)$

$$
C(t ; n)=p(t ; n) U(t ; n)
$$

We underline that statistical moments of the trade value $C(t ; n)$ and volume $U(t ; n)$ are determined by the conventional frequency-based probability measure (6.11). However, 
relations (6.12) define the market-based price statistical moments $p(t ; n)$ (6.12) that do not match frequency-based approach. Only if all trade values $U\left(t_{i}\right)$ during the averaging interval $\Delta$ equal unit (or constant): $U\left(t_{i}\right)=1, i=1, \ldots N$ - only in this case price statistical moments $p(t ; n)$ match frequency-based price probability (6.1) and are determined by relations (6.13)

$$
p(t ; n)=\frac{1}{N} \sum_{i=1}^{N} p^{n}\left(t_{i}\right)
$$

However, requirements $U\left(t_{i}\right)=l$ (or constant) are far from market realities.

We underline that assumptions of no correlations between $n$-th power of price $p^{n}\left(t_{i}\right)$ and $n$-th power of trade volume $U^{n}\left(t_{i}\right)$ time-series during the averaging interval $\Delta(6.10)$ define (6.12). We remind that the same assumptions of no correlations between price $p\left(t_{i}\right)$ and trade volume $U\left(t_{i}\right)$ time-series during the interval $\Delta$ defines the VWAP. We consider these problems in (Olkhov, 2021a; 2021b; 2021c; 2022) and refer there for details.

It is well know that the set of all price statistical moments $p(t ; n)(6.12), n=1,2, \ldots$ determines all statistical properties of the price as random variable and thus determines Taylor series of price market-based characteristic function $F(t ; x)$ (Shephard 1991; Shiryaev 1999; Klyatskin 2005; 2015):

$$
\begin{aligned}
& F(t ; x)=1+\sum_{i=1}^{\infty} \frac{i^{n}}{n !} p(t ; n) x^{n} \\
& p(t ; n)=\left.\frac{d^{n}}{(i)^{n} d x^{n}} F(t ; x)\right|_{x=0}
\end{aligned}
$$

Fourier transforms of the approximations of the characteristic function $F_{k}(x ; t)$ determined by sum of finite number $k$ of Taylor series (6.14)

$$
F_{k}(t ; x)=1+\sum_{i=1}^{k} \frac{i^{n}}{n !} p(t ; n) x^{n}
$$

determine approximations of the market-based price probability measure $\eta_{k}(t ; p)$ :

$$
\eta_{k}(t ; p)=\int d x F_{k}(t ; x) \exp (-i x p) \quad ; \quad F_{k}(t ; x)=\int d p \eta_{k}(t ; p) \exp (i x p)
$$

We use variable $t$ to underline that the market-based price characteristic function $F(t ; x)(6.14)$ and approximation of the market-based price probability measure $\eta_{k}(t ; p)$ (6.16) describe properties of price as a random variable inside the averaging interval $\Delta(6.2 ; 6.3)$. We refer for further details to (Olkhov, 2021a; 2021b; 2022).

Introduction of the market-based approach to definition of the price statistical moments $p(t ; n)$ (6.12) and price characteristic function $F(t ; x)(6.14)$ uncovers the hidden complexities of conventional treatment of the math expectation $E[.$.$] (2.1) for the consumption-based asset$ pricing model and the basic pricing equation (2.4) (Cochrane, 2001). As we show above, the market-based price math expectations should be determined by statistical moments of the random time-series that record the market trade value and volume during the interval $\Delta$. 
Duration of the averaging interval $\Delta$ has a significant impact on properties of the trade statistical moments (6.11) and thus on the properties of the basic pricing equation. The mean price $p_{0}(t)$, price volatility $\sigma_{p}^{2}(t)$ and autocorrelation $B_{p}\left(t_{1}, t_{2}\right)$ depend on the market trade statistical moments (6.11) averaged during the time interval $\Delta$.

Usage of Taylor series simplifies the assessments of math expectation of the utility function (2.9) and replaces math expectations of utility functions by utility functions at mean consumption values. For example, math expectation $E\left[u^{\prime}\left(c_{t}\right) p\right](2.8)$ is approximated by

$$
E\left[u^{\prime}\left(c_{t}\right) p\right] \sim u^{\prime}\left(c_{t ; 0}\right) p_{0}(t)-\xi u^{\prime \prime}\left(c_{t ; 0}\right) \sigma_{p}^{2}(t)
$$

However, correct assessments of the mean price $p_{0}(t)$ (3.5), price volatility $\sigma_{p}^{2}(t)$ (3.2) and autocorrelation $B_{p}\left(t_{1}, t_{2}\right)(4.10 ; 4.13)$ require usage of the market-based definition of price statistical moments (6.12). The market-based approach to the price probability increases complexity of modelling asset pricing, price volatility and price autocorrelation but clarifies their direct dependence on the market trade stochasticity.

\section{Conclusion}

The main contribution of this paper is the demonstration that the conventional consumptionbased asset pricing model (Cochrane, 2001) allows assessments of the price (4.10) and payoff autocorrelation (5.9) as factors of the basic pricing equations (4.12) and (5.8) respectively. As long as the consumption-based pricing model (Cochrane, 2001) demonstrates similarity with other versions as Intertemporal CAMP (ICAPM), Arbitrage pricing theory (APT) and etc., it allows assert that above results can be derived within other pricing models as well. One should regard direct consideration of the averaging interval $\Delta$ as starting point of any asset pricing models as necessary tool for the averaging or smoothing time-series. Usage of Taylor series expansions during the averaging interval allows consider two or more serial trades with assets and helps derive all the above results using different versions of pricing models.

We assume that our reasons in favor of the market-based averaging of the price time-series require reconsideration of the methods and results of most pricing models. Different treatments of math expectation using the frequency-based or the market-based approach result in different assessments and different treatments of the price-volume relations in particular. Numerous studies (Karpoff, 1987; Gallant, Rossi and Tauchen, 1992; Odean, 1998; Gopikrishnan, et.al, 2000; Podobnik, et.al, 2009; DeFusco, Nathanson and Zwick, 2017) assess price-volume relations on base of the frequency-based approach. However, as we outline, the usage of VWAP implicitly assumes no correlations between trade volume and 
price time series (6.10). We underline that different treatment of the price averaging becomes the origin of that contradiction and result in different valuations of price statistical moments. The reasons in favor of the market-based approach to price probability and definition of price statistical moments $(6.11 ; 6.12)$ have general meaning for any description of the averaged time-series. Usage of moving average do not change anything substantial but delivers smooth approximation of the averaging based on simple sequence of averaging interval $\Delta$ without overlapping. As we show, the market-based price averaging leads to substantial revision of the "classical grounds" of option pricing (Olkhov, 2020) and uncovers tough complexity on the way for development of the reasonable macroeconomic theory (Olkhov, 2018; 2019a; 2019b; 2021c; 2021d).

Moreover, in our view, almost insurmountable difficulties are related not with description of economic system with diverse interacting economic variables, numerous trades between almost infinite number of economic agents, trades with various commodities, goods, services and etc. Al that can be regularized, ordered, enumerated and described. The most complexity and the permanent source of the perturbations, distortions and unbelievable stochasticity are related with simple definition of economics as a social science. The beliefs and trusts, expectations and preferences, habits and fashions, avarice and preconceptions of the economic agents determine the trade decisions, market strategies, choice of benchmarks and desired forecasts. Human nature is the source of main and irremediable complexity that prevents development of any rational and reasonable economic theory.

In particular, only agent's beliefs and habits determine what method should be used to assess price time-series math expectation, volatility or autocorrelation. Usage of the conventional and familiar frequency-based assessment of mean price and price volatility will continue, no matter that this method has almost nothing common with market price stochasticity.

However, market-based assessment of price statistical moments $(6.11 ; 6.12)$ and consequence modelling of the mean price, price volatility and autocorrelation can help rare braves develop pricing theory, that follows market laws. That requires selection of particular time averaging interval $\Delta$, collecting economic and financial time-series and averaging during $\Delta$ using the market-based approach. The complexity of this approach, among other problems, is that the market trades follow agent's decisions, but the asset pricing should follow time-series records of the performed market trades and then serve as a ground for agent's trade decisions. That mutual dependence is a toughie problem.

We hope that the collisions between results of the conventional frequency-based and the market-based averaging may help further develop the financial market theory. 


\section{References}

Andersen, T.G., Bollerslev, T., Christoffersen, P.F., and Diebold, F.X. (2006). Volatility and Correlation Forecasting, in G. Elliot, C.W.J. Granger, and Allan Timmermann (eds.)

Barillas, F. and J. Shanken, (2018). Comparing Asset Pricing Models. J.Finance, 73 (2), 715 754

Berkowitz, S.A., Dennis, E., Logue, D.E., Noser, E.A. Jr. (1988). The Total Cost of Transactions on the NYSE, The Journal of Finance, 43, (1), 97-112

Buryak, A., Guo, I. (2014). Effective And Simple VWAP Options Pricing Model, Intern. J. Theor. Applied Finance, 17, (6), 1450036, https://doi.org/10.1142/S0219024914500356 Busseti, E., Boyd, S. (2015). Volume Weighted Average Price Optimal Execution, 1-34, arXiv:1509.08503v1

Campbell, J.Y., Grossman, S.J. and J.Wang, (1992). Trading Volume and Serial Correlation in Stock Return. NBER WP 4193, Cambridge, MA., 1-45

Campbell, J.Y. (2000). Asset Pricing At The Millennium. NBER, WP 7589, Cambridge, 1-75 Campbell, J.Y. (2014). Empirical Asset Pricing: Eugene Fama, Lars Peter Hansen, and Robert Shiller. WP, Dep. Economics, Harvard University, 1-46

CBOE, (2021a). VWAP Calculation for VX Futures Daily Settlement Prices, Ref.ID: C2020110601, 1-2

CBOE, (2021b). Cboe Russell 2000 Conditional BuyWrite Index, 1-8

Cochrane, J.H. (2001). Asset Pricing. Princeton Univ. Press, Princeton, US

Cochrane, J.H., Culp, C.L. (2003). Equilibrium Asset Pricing and Discount Factors: Overview and Implications for Derivatives Valuation and Risk Management. In: Modern Risk Management. A History, Ed. S.Jenkins, 57-92

Cochrane, J.H. (2022). Portfolios For Long-Term Investors, Rev. Finance, 26(1), 1-42

DeFusco, A.A., Nathanson, C.G. and E. Zwick, (2017). Speculative Dynamics of Prices and Volume, Cambridge, MA, NBER WP 23449, 1-74

Diebold, F.X. and G. Strasser, (2010). On The Correlation Structure Of Microstructure Noise: A Financial Economic Approach, NBER, WP 16469, Cambridge, MA, 1-65 Fama, E.F. (1965). The Behavior of Stock-Market Prices. J. Business, 38 (1), 34-105 Fama, E.F. (2014). Two Pillars of Asset Pricing, American Economic Review, 104(6), 14671485

Forbes, C, Evans, M., Hastings, N., Peacock, B. (2011). Statistical Distributions. Wiley Fox, D.R. et al. (2019). Concepts and Methods of the U.S. National Income and Product Accounts, BEA, US DoC, 1-449 
Friedman, D.D. (1990). Price Theory: An Intermediate Text. South-Western Pub. Co., US Gallant, A.R., Rossi, P.E. and G. Tauchen, (1992). Stock Prices and Volume, The Review of Financial Studies, 5(2), 199-242

Goetzmann, W.N., Li, L. and K. G. Rouwenhorst, (2001). Long-Term Global Market Correlations. NBER, WP 8612, Cambridge, MA., 1-52

Goldsmith, R.W., Lipsey, R.E. (1963). Asset Prices and the General Price Level, NBER, 166 - 189, in Studies in the National Balance Sheet of the United States, Ed. Goldsmith, R.W. and R. E. Lipsey

Gopikrishnan, P., Pleroua, V., Liua, Y., Amarala, L.A.N., X. Gabaix, X. and H.E. Stanley, (2000). Scaling and correlation in financial time series, Physica A, 287, 362-373

Karpoff, J.M. (1987). The Relation Between Price Changes and Trading Volume: A Survey. The Journal of Financial and Quantitative Analysis, 22 (1), 109-126

Kendall, M.G and A.B. Hill, (1953). The Analysis of Economic Time-Series-Part I: Prices. Jour. Royal Statistical Soc., Series A, 116 (1), 11-34.

King, W.I. (1917). The Correlation of Historical Economic Variables and the Misuse of Coefficients in this Connection. Publications of the American Statistical Association, 15 (120), $847-853$

Klyatskin, V.I. (2005). Stochastic Equations through the Eye of the Physicist, Elsevier B.V. Klyatskin, V.I. (2015). Stochastic Equations: Theory and Applications in Acoustics, Hydrodynamics, Magnetohydrodynamics, and Radiophysics, v.1, 2, Springer, Switzerland Lind, N. and N. Ramondo, (2018). Trade With Correlation, NBER, WP 24380, Cambridge, MA, 1-64

Liu,Y., Cizeau, P., Meyer, M., Peng, C-K. and H. E. Stanley, (1997). Correlations in Economic Time Series. Physica A, 245, 437-440

Llorente, G., Michaely R., Saar, G. and J. Wang. (2001). Dynamic Volume-Return Relation of Individual Stocks. NBER, WP 8312, Cambridge, MA., 1-55

Lo, A.W., (1987). Long-term Memory in Stock Market Prices. NBER WP 2984, Cambridge, MA., 1-47

Mantegna, R.N. and H. E. Stanley, (2000). An Introduction To Econophysics. Correlations And Complexity In Finance. Cambridge Univ.Press, 1-147

Michaely, M. (1971). Appendix: A Few Experiments with Formal Correlation Analysis, 281287 in Ed. Michaely, M., The Responsiveness of Demand Policies to Balance of Payments: Postwar Patterns, NBER, Cambridge, MA.

Merton, R.C. (1973). An Intertemporal Capital Asset Pricing Model, Econometrica, 41, (5), 
$867-887$

Nasdaq, (2020). Nasdaq Index Policies \& Procedures. Calculation Manual - Equities \& Commodities

Odean,T. (1998). Volume, Volatility, Price, And Profit When All Traders Are Above Average, The Journal of Finance, LIII, (6), 1887-1934

Olkhov, V. (2018). How Macro Transactions Describe the Evolution and Fluctuation of Financial Variables, Int. J. Financial Stud., 6 (38), 1-19

Olkhov, V. (2019a). Economic And Financial Transactions Govern Business Cycles. ACRN Oxford Journal of Finance\&Risk Perspectives. 8, 1-20

Olkhov,V. (2019b). Financial Variables, Market Transactions, and Expectations as Functions of Risk. Int. J. Financial Stud., 7, 66; 1-27

Olkhov, V., (2020), Classical Option Pricing and Some Steps Further. MPRA, WP105431, 1-16, https://mpra.ub.uni-muenchen.de/105431/

Olkhov, V. (2021a). Three Remarks On Asset Pricing. SSRN WP3852261, 1-24. https://ssrn.com/abstract=3852261

Olkhov, V. (2021b). To VaR, or Not to VaR, That is the Question. SSRN, WP3770615, 1-14. https://ssrn.com/abstract=3770615

Olkhov, V. (2021c). Theoretical Economics and the Second-Order Economic Theory. What is it? SSRN, WP 3975585, 1-14. https://ssrn.com/abstract=3975585

Olkhov, V. (2021d). Price, Volatility and the Second-Order Economic Theory. ACRN Jour. Finance \& Risk Perspectives, Sp. Issue, 18th FRAP Conference, 10, 139-165

Olkhov, V. (2022). Introduction of the Market-Based Price Autocorrelation. SSRN, WP 4035874, 1-13. http://ssrn.com/abstract $=4035874$

Plerou, V., Gopikrishnan, P., Rosenow, B., Amaral, L.A.N. and H. E. Stanley, (2000). Econophysics: Financial time series from a statistical physics point of view, Physica A, 279 443-456

Podobnik, B., Horvatic, D., Petersena, A.M. and H. E. Stanleya, (2009). Cross-correlations between volume change and price change, Proceed. National Academy of Sci., US (PNAC), 106 (52), 22079-22084

Quinn, D.P. and H-J. Voth, (2008). A Century of Global Equity Market Correlations. American Economic Review, 98 (2), 535-540

Sharpe, W.F., (1964). Capital Asset Prices: A Theory of Market Equilibrium under Conditions of Risk, Jour. Finance, 19 (3), 425-442 
Shephard, N.G. (1991). From Characteristic Function to Distribution Function: A Simple Framework for the Theory. Econometric Theory, 7 (4), 519-529

Shiryaev, A.N. (1999). Essentials Of Stochastic Finance: Facts, Models, Theory. World Sc. Pub., Singapore. 1-852

Walck, C. (2011). Hand-book on statistical distributions. Univ.Stockholm, SUF-PFY/96-01 